Goldschmidt 2021 Abstract

https://doi.org/10.7185/gold2021.3169

\section{Race, Racism, and Barriers to the Participation of Black People in the Geological Sciences: How bad is it? Should we do something about it? What can we do about it?}

NATASHA J DOWEY ${ }^{1}$ CHRISTOPHER AIDEN-LEE JACKSON $^{2}$, JENNI BARCLAY ${ }^{3}$, BEN FERNANDO ${ }^{4}$, SAM GILES $^{5}$, JACQUELINE HOUGHTON ${ }^{6}$, ANJANA KHATWA ${ }^{7}$, ANYA LAWRENCE ${ }^{8}$, KEELY MILLS $^{9}$, ALICIA NEWTON ${ }^{10}$, STEPHEN ROGERS ${ }^{11}$ AND REBECCA WILLIAMS ${ }^{12}$

${ }^{1}$ Sheffield Hallam University

${ }^{2}$ Imperial College

${ }^{3}$ University of East Anglia

${ }^{4}$ Oxford

${ }^{5}$ Birmingham

${ }^{6}$ Leeds

${ }^{7}$ Wessex Museums

${ }^{8}$ The University of Birmingham

${ }^{9}$ British Geological Survey

${ }^{10}$ Geological Society of London

${ }^{11}$ Keele

${ }^{12} \mathrm{Hull}$

Presenting Author: C.jackson@imperial.ac.uk

Geoscientists have a key role to play in the great challenges of the 21 st Century, but solving these problems requires diverse collaborations and engagement with stakeholders from all backgrounds, both in the fundamental science and its implementation. Yet, in the Global North, the geosciences are disproportionally white, a result of both historic systemic racism that impacts academia as a whole and discipline-specific issues that make us less inclusive to many underrepresented groups. This underrepresentation is well-documented in the US, but comparatively less well documented in the UK. Our analysis of data from the UK Higher Education Statistics Authority (HESA) paints a similarly dismal picture.

In the 2018/19 academic year, the proportion of UK-domiciled Black and minority ethnic (BAME) students enrolled in UK HE overall was $24.8 \%$ at undergraduate level, dropping to $18.1 \%$ in postgraduate research. The physical sciences had 16.8\% BAME student undergraduate enrolment in 2018/19, dropping to $12.1 \%$ at research postgraduate level. BAME enrolment in geology was far lower than the than that of the physical sciences, with $10.1 \%$ at undergraduate and $10.4 \%$ at postgraduate. Physical geography had only $8.5 \%$ BAME representation on undergraduate courses and $5.2 \%$ in postgraduate research.

There are a number of barriers to entry to the geosciences that will disproportionally affect those from minority backgrounds in the UK, including pre-university access to the countryside for Black students, and a range cultural and cost issues related to often compulsory geoscience fieldwork.

Amongst a range of other mechanisms, ringfenced funding opportunities are the key to supporting students from BAME backgrounds into postgraduate research. Paid internships allow students to build links with industry professionals and choose specialties, while targeted doctoral studentships can combat implicit bias in existing doctoral training programs.

Finally, we need to acknowledge the hostile environments that deter BAME students from both applying to, and continuing with, our discipline. We must address personal and structural biases and go beyond this to be actively anti-racist. We must act now, and have those difficult conversations, to create a modern geoscience research culture that reflects the diverse nature of the planet we study. 